to the full. But if the real objective is a radical recasting of the pattern of urban transport, the solution is much more likely to be found in sociology and economics than in technical innovation pure and simple.

Another of the committees at the Ministry of Transport is, in this sense, a little nearer the mark. On the same day as the appearance of the report on tiny motor cars, the ministry published a report of a study of how the flow of road traffic in British cities, particularly London, might be controlled by the impositions of charges of various kinds (Better Use of Town Roads, HMSO, 7s. 6d.). The starting point for this argument is the calculation, not entirely above reproach, that the restraint of private motor cars in cities like London would allow other traffic to move much more quickly and economically. On one version of the argument, for example, a daily charge of $6 s$. for each private car entering central London would bring about a saving of $£ 5$ million a year from improved efficiency-and a cash revenue of the same amount. Even though these arguments are grossly optimistic, they are probably worth more detailed consideration. It is, after all, something to be grateful for that the ministry's committee has retreated from the old impractical idea that all vehicles might be charged an amount identical with the economic value of the use made of the roads. But if the goal is really the "elimination" of the motor car commuter, the ministry has to acknowledge that there will be a serious economic disadvantage in a system in which the grossly inadequate public transport systems now operating in British cities are the best means of transport accessible to all but millionaires.

Here too the ministry has been dazzled by oversimple considerations, most of them arithmetical. It is, however, entirely possible that much greater improvements in the over-all quality of urban transport could be obtained by comparatively easy administrative actions. Recognizing, for example, that most city transport systems are entirely adequate except at the morning and evening periods of peak travel, cheap fares for off-peak travel on public transport could bring great benefits. Comparatively small amounts of money spent on the speed and even the comfort of bus services and subways could bring important gains. Pricing policies which would cheapen the cost of travel within cities along trunk routes could help enormously to put commuter cars at a disadvantage, as could a sharper distinction between trunk routes (usually subway lines) and more local distribution networks (based more often on buses and taxis). Keeping public transport systems running late at night could be an economic gain if, on paper, a monetary loss. Using one part of the transport system to subsidize another is entirely respectable.

But which of the many possible solutions should the administrators try out? On the face of things, this is a daunting question. In reality, however, there is plenty to be done. A much more thorough understanding of how people use city transport of all kinds is an urgent need. Most of the British surveys so far have been designed to measure the volume of traffic and not to understand why it exists, but only a sensitive appreciation of the function of urban transport will make it easy to divert it into more convenient patterns. Then there is also a need for experiment with administrative measures such as unusual pricing policies for public transport. Certainly there is more reason to hope that intelligent management of public transport policies could do more to rationalize the pattern of city transport than any artificial network of roads for tiny motor cars. In the long run, imaginative policies on transport in cities could help to shape cities into more efficient communities in which urban transport would be obviously a convenience and not a nuisance as well. But this will require that the Ministry of Transport should hold much more rigorously than it does to the view that city transport, public and private, must be dealt with as an integrated service designed to satisfy the needs of real people. In cities, if not elsewhere, there is no truth in the epigram that to travel is better than to arrive.

\section{NO COMPARISON}

THE report of the OECD on the state of science in the United Kingdom and West Germany (see page 9) is something of a disappointment, coming as it does in a series of public documents which has done much to direct the attention of governments to important problems in the administration of science. A part of the trouble seems to have been that the decision to com. pare the two countries has led to an artificial emphasis on such tangible differences as may be found to exist. The danger that this would happen was appreciated before the study was begun, but foresight has not prevented the two groups of examiners from giving far too much importance, for example, to the structural differences in the machinery for the administration of science in Germany and in the United Kingdom. At the same time the report is curiously unhelpful about differences which are at once striking and potentially important. Why, for example, does German industry contribute more towards scientific research than its counterpart in the United Kingdom? The examiners of the OECD would have had a friendly reception from the British Ministry of Technology if they had been able to supply a pithy answer. No doubt there are some at least in West Germany who would have been equally receptive of a sympathetic explanation why expenditure on university research seems occasionally to have been less productive than it might have been. By paying less attention than it should have done to matters like these, the OECD report has tended to exaggerate the similarities as well as the differences between the two countries.

The study of science policy in Germany and in Britain was also, however, complicated by the importance the two governments attach to science and technology. Both of them are earnest seekers after better science policies, especially just now. The OECD 
is quite right in pointing out that each of them gives a different emphasis to the objectives of policy-the British Government, for example, is most of all concerned to win some cash return from science and technology. The two governments have in common, however, the need to grapple with exceedingly complicated problems. Science policy runs into educational policy at one end of the spectrum and into taxation policy at the other. In circumstances like these, broad generalizations are unlikely to be convincing. Thus the way in which the OECD report rightly points to the cramping influence of specialization at British secondary schools will bring comfort to some of those who are engaged in battles to see things changed, but a report like this must necessarily seem somewhat remote and even oracular. Much the same is true of the chief recommendation of change in the administration of science in Britain-the claim that there should be a closer link between the empires maintained respectively by the Department of Education and Science and by the Ministry of Technology. A few years from now there may be a strong case for an amalgamation of these interests, but in spite of the enthusiasm of the House of Lords for this cause two weeks ago, it would be wrong to reunite science and technology under the Ministry of Technology until that recent creation knows much more clearly than at present what kinds of policies to pursue. Indeed, if the Ministry should accept the logic of its recent discovery that Keynes has as much to say as Rutherford about the translation of technology into money, it may grow to be more closely connected with the Department of Economic Affairs than with the Department of Education and Science. Then nobody knows what function the Central Advisory Council on Science and Technology will be able to work out for itself. Will Sir Solly Zucker man be a co-ordinator or simply a harassed referee? These are fascinating questions, but they cannot unfortunately be answered by appealing to what may be described as recorded science policy. In this sense OECD has probably learned as much from its examinations as have the two countries most concerned.

\section{DOES CHINA EXIST?}

FEw people are well placed to know what is happening in mainland China, and one result is that even quite simple travellers' tales are eagerly sought after by those who have been compelled to stay at home. The article by Dr K. Mendelssohn on page 10 is more than a mere anecdote, of course, but it also serves to add another morsel of flesh to the crude skeleton which must at present serve as an appreciation by outsiders of the present condition of science in China. No doubt the Chinese themselves would be alarmed to know how strangely many of their recent policies have seemed from overseas. On the face of things, for example, it is hard to reconcile the policy centred on the communes in the early sixties with the character of technology as it is known in the West. By the same test, it is not easy to see how the interests of working scientists in China will have been affected by the social phenomenon called the Cultural Revolution. Will they now be better placed to work effectively? Or will they find that too much energy must be spent in the pursuit of orthodoxy? These are important questions, for it is only a matter of time, though perhaps a long time, before Chinese scientists are fully integrated within the international community. It is disappointing that these questions are so hard to answer.

Who is to blame? The most obvious thing to say is that there is no obvious reason why the mainland Chinese should at this stage pay close attention to the international interests of their scientists. They have other fish to fry. Yet there is plenty of evidence in the past few years of a wish somehow to demonstrate that science and technology are flourishing in mainland China. There was, for example, quite open boasting a year ago about the way in which a group of Chinese chemists had been able to synthesize insulin, and, in retrospect, there was plainly plenty to boast about. Although the synthesis of insulin was completed almost at the same time in the United States, it looks as if the Chinese group had to contend with more serious difficulties; a good many of the natural intermediates in the synthesis of insulin were not easily obtainable, for example. It is also understandable that the government at Peking should be eager to point out the cleverness with which technical people have been able to make thermonuclear weapons a mere decade after what seemed at the time to be a great step forward in nuclear technology-the opening of a modest research reactor in 1958 . Yet the scientific literature which is now increasingly available, often in translation, shows that these events are not strictly occasions for surprise. There is plenty of talent in the universities and institutes, though there is a long way to go before the research is being carried out on a scale which matches the size of China and the energy of its population.

In circumstances like these, patience is evidently the greatest need. It is too soon to expect that Chinese scientists should mix more willingly with the rest of the world. There is, however, good reason why they should be less suspicious of a continuing relationship with institutions elsewhere. After all, the Chinese themselves must know how much they gained in the fifties from their ability to move comparatively easily to institutes like that at Dubna in the Soviet Union. By now they should also have discovered that even in Western Europe, scientists do not always have horns growing out of their heads. Such exchange agreements as there have been, however, have so far been discouraging. Chinese visitors to laboratories in Europe have kept themselves in isolation. Visitors to Peking have sometimes found themselves kicking their heels in hotels. Language is an obvious difficulty, but only half the story. Is it too much to hope that exchange agreements will function more generously now that the first thermonuclear weapon has been exploded ? That would be a curious irony. 